\title{
Cross-sectional Study to Assess Psychological Impact of COVID-19 on Health Care Staff Working in a Tertiary Care Teaching Hospital
}

\author{
Girija Mahale ${ }^{1 *}, Y_{\text {oshita Thadaney }}^{2}$, Nidhi Purohit $^{3}$
}

\section{ABSTRACT}

The COVID-19 pandemic has placed an enormous strain on healthcare professionals who have been at war with the virus since a year now. It was important to understand the mental health care impacts so that timely interventions could be provided to those who were in need of support. This would provide them with the much-needed support as well as prevent them from burn out. However, understanding healthcare professionals' innate capacities of resilience and proactive coping was important to provide a holistic picture. This project studied the stress, anxiety, resilience and proactive coping levels of 151 hospital staffers at a designated COVID19 tertiary care teaching institution in Pune district. They were administered the four scales and it was found that most were experiencing moderate stress levels, normal levels of anxiety and scored high on resilience and proactive coping measures. A significant negative correlation between anxiety and resilience and positive correlation between resilience and coping was found. This study shows that adequate support from the hospital, innate reserves of resilience and adequate coping techniques were protective factors, preventing the distress levels from culminating into mental illness. The sample's mean age of 34 years could have also been a positive factor. However, it is important to further study the chronic effects of stress on mental health and burnout, given the pandemic is ongoing.

\section{Keywords: Healthcare Professionals, COVID-19, Mental Health}

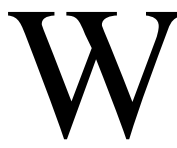

ith the start of 2020, the world witnessed an upsurge of the novel Coronavirus (COVID-19) disease, one that was infectious. The respiratory disease started spreading from China and rather rapidly engulfed other countries, including India, deeming Coronavirus a serious pandemic. The struggle to develop a vaccine has left the world treating symptoms of Coronavirus to the best of their abilities (Gallagher, 2020).

\footnotetext{
${ }^{1}$ M.D. (Psy. Med), FRANZCP, Consultant Psychiatrist, heads the Symbiosis Centre for Emotional Wellbeing, Symbiosis International (Deemed) University, India

${ }^{2}$ M.Sc. Clinical Psychology, Symbiosis Centre for Emotional wellbeing, Symbiosis International (Deemed) University, India

${ }^{3} \mathrm{PhD}$, Clinical Psychologist, Symbiosis Centre for Emotional wellbeing, Symbiosis International (Deemed) University, India *Corresponding Author
}

Received: April 23, 2021; Revision Received: May 24, 2021; Accepted: June 21, 2021

(C) 2021, Mahale G., Thadaney Y. \& Purohit N.; licensee IJIP. This is an Open Access Research distributed under the terms of the Creative Commons Attribution License (www.creativecommons.org/licenses/by/2.0), which permits unrestricted use, distribution, and reproduction in any Medium, provided the original work is properly cited. 
In the first three months of the spread of COVID-19, there were nearly one million cases and 50,000 deaths (COVID-19, MERS \& SARS, 2021). Due to the highly communicable nature of the disease, governments of various countries from China, Italy, the United States of America, India, and many more declared nationwide lockdowns in whole or parts of the country to prevent rampant spread of the disease. Despite a nationwide lockdown in India, as per the national data checked on the 22nd of April 2020, India has seen approximately 20,000 cases of coronavirus with a mortality of 640 patients (\#India Fights Corona COVID-19, 2021). This has created excessive pressure on health care professionals who have been fighting relentlessly and putting in more hours than usual in an attempt to treat the ever-increasing numbers of COVID-19 patients (Bhushan, 2020).

Given the above, it is evident that a pandemic of this magnitude would have immense psychosocial effects on health care workers, be it doctors to ward boys. Due to the rampant increase in numbers, they are working extra hours, which inherently limits the time they spend with their families and support systems. They also fear infecting their family members and have to take extreme precautions such as practicing social distancing even with their family members in their households. Since the disease is communicable, the hospital staff need to don themselves in personal protective equipment (PPE) whilst around COVID-19 positive patients. Having to constantly wear personal protective equipment such as eye protection, facemasks and isolation gowns among others for extended hours is bound to cause discomfort and leave some with scars for days. However, this is the least of their worries as hospitals are facing a shortage of PPE supplies and health care professionals worry about PPE quality as well. The lack of specific drugs to treat COVID-19 patients is yet another added stressor for doctors who are trying tirelessly to treat all their patients as effectively as possible. Due to the lack of hospital resources and a swift increase in the number of cases, doctors are also being pressurized to prioritize patients who get treatment first. These are only some of the stressors being experienced by our health care professionals, therefore it is of utmost importance to understand their stress and anxiety levels as well as the way they cope with the constant stressors being bombarded their way.

As per the American Psychological Association (APA), stress is the physiological or psychological response to internal or external stressors (Stress, n.d). APA also defines anxiety as an emotion that has features of worrying thoughts, physical changes like increased heart rate and feelings of tension (Anxiety, n.d). And finally, APA describes coping as usage of behavioral and cognitive strategies to manage the demands of a situation when these are appraised as stressful or exceeding one's resources (Coping, n.d.). It is important to study these variables as experiencing anxiety and stress is a normal response to an event of this nature. Coping with anxiety would shed light upon whether these emotions experienced by our frontline workers are being managed healthily or not. If they are not managed in a healthy and timely manner, they could lead to psychological as well as physical disorders and cause a serious impediment in functionality. Understanding their current stress and anxiety levels and the resources they use to deal with these would provide the required information for mental health care professionals as well as policymakers to intervene at an early stage if required. Hence, if it is found that the health care professionals in the current study are under distress of any sort, early intervention and assistance to manage their mental health would be ideal in the prevention of burnout and other adverse health effects as mentioned above. It would also help in dictating whether the government would benefit from implementing policies that would cater to the mental health of health care professionals whilst they fight against COVID19 versus the after-effects that COVID-19 could have on them.

(c) The International Journal of Indian Psychology, ISSN 2348-5396 (e)| ISSN: 2349-3429 (p) | 1401 


\section{Cross-sectional Study to Assess Psychological Impact of COVID-19 on Health Care Staff Working in a Tertiary Care Teaching Hospital}

However, another variable that could and should be considered here is resilience. As per APA, psychologists define resilience as "the process of adapting well in the face of adversity, trauma, tragedy, threats, or significant sources of stress" (Resilience, n.d.). These stressors can be of various kinds such as relationship problems, health problems, workplace, and financial stressors. For these reasons, resilience is also known as the ability to bounce back from adversity. Considering our front-line workers work in high-stress environments, with or without the presence of a pandemic, resilience must be part of their psychological make-up. A study conducted on doctors in the United Kingdom to test their levels of resilience found that for the 283 doctors that were tested, the mean resilience was higher than the population norms (McCain, McKinley, Dempster, Campbell \& Kirk, 2018). Therefore, studying this positive factor would also enable us to understand the innate ability of our frontline health practitioners to cope with stress and enable mental health professionals to build this resource whilst employing specific intervention strategies.

\section{REVIEW OF LITERATURE}

In 2003, the world saw an outbreak of Severe Acute Respiratory Syndrome (SARS) which engulfed 26 countries resulting in around 8000 cases. A study conducted in Toronto aimed to study the psychosocial impacts that SARS had on health care workers in one of their largest tertiary care institutions. Since they were at high risk to contract the infection, spread it to family members, spend long hours working and wearing uncomfortable protective gear, it was important to understand how these factors were affecting their mental health. It was found that $148(29 \%)$ of respondents were experiencing some form of emotional distress, a higher proportion being part-time workers due to limited information being received, lesser involvement in hospital activities as well as lesser support from their colleagues (Nickell et al., 2004).

In a 2020 study on medical workers in Wuhan during the COVID-19 outbreak, it was found that healthcare workers were experiencing symptoms of anxiety, insomnia, stress, depressive, denial, anger, and fear due to the situation. These psychological consequences not only affect the medical workers' understanding, attention, and decision-making skills, which would hamper the fight against COVID-19 but would also have a lifelong effect on their wellbeing (Kang et al., 2020). In another article review performed, it was found that healthcare professionals were at a significant jeopardy of experiencing mental health outcomes through the COVID-19 pandemic. The reasons stated in this study were lengthy working hours, danger of infection, scarcities of protective equipment, physical fatigue, loneliness and staying away from families (Rajkumar, 2020).

A multicentre Chinese survey that studied 1563 medical staff, found the rates of depression, assessed to be $792(50 \cdot 7 \%)$, of anxiety as $699(44.7 \%)$, of insomnia as $564(36 \cdot 1 \%)$, and of stress-related symptoms assessed as 1147 (73.4\%). These conclusions are pertinent in supporting health policymakers to apportion health resources and advance appropriate interventions for medical staff who have been psychologically affected (Liu et al., 2020).

Another cross-sectional, web-based survey conducted in China during the COVID-19 pandemic found that $1013(44.37 \%)$ had symptoms of depression, 1051 (46.04\%) had symptoms of anxiety, $647(28.75 \%)$ had symptoms of insomnia and 274 (56.59\%) reported general psychological problems, in healthcare workers. Attention to neutral or negative information regarding COVID-19, reception of negative feedback from friends, families who 


\section{Cross-sectional Study to Assess Psychological Impact of COVID-19 on Health Care Staff Working in a Tertiary Care Teaching Hospital}

joined front-line roles, and reluctance to take on front-line roles, if provided a choice were three main factors for these issues (Que et al., 2020).

To measure the impact of mental health consequences and related factors among health care professionals treating patients in China exposed to COVID-19, a survey-based, cross-sectional region-stratified study was carried out. Health care workers in hospitals catering to wards or fever clinics for patients with COVID-19 participated only. 634 (50.4\%) reported symptoms of depression, $427(34.0 \%)$ insomnia, $560(44.6 \%)$ anxiety and $899(71.5 \%)$ distress. Females, health care workers, frontline, nurses and persons situated in Wuhan, China, reported higher levels of mental health symptoms than others (Lai et al., 2020).

In a Turkish study, levels of hopelessness and anxiety of healthcare professionals and nonhealthcare professionals and the aspects affecting them were evaluated during the COVID-19 pandemic. 2156 individuals made up the sample size out of which $1121(52 \%)$ were healthcare workers. The levels of state anxiety and hopelessness of healthcare professionals were greater than those of non-healthcare professionals. Hopelessness was greater in nurses than doctors, and state anxiety levels were also higher than both physicians and allied healthcare professionals. Levels of hopelessness and anxiety were greater for those living with a highrisk individual, women, ones whose income decreased, and those who had trouble in caring for their children. Anxiety was an important predictor of hopelessness. Higher working hours were a significant factor causing anxiety. In conclusion, the mental health of healthcare professionals in the COVID-19 pandemic was more affected in comparison to society. Nurses were however the most affected in comparison to other healthcare professionals (Hacimusalar, Kahve, Yasar \& Aydin, 2020).

A cross-sectional, descriptive, and comparative plan was prepared to explore acute stress disorder (ASD), coping self-efficacy, and following psychological distress among nurses during COVID-19 through a web-based survey. 448 Jordanian nurses (327 females) completed the questionnaire. The results revealed that 308 (64\%) were experiencing ASD and thus were at risk for Post-Traumatic Stress Disorder (PTSD) predisposition. 197 (41\%) nurses were also experiencing noteworthy psychological symptoms. Among the sample, ASD, coping self-efficacy and age significantly predicted psychological distress. More precisely, younger nurses were more likely to experience psychological distress than older nurses. Higher scores on ASD showed more consequential psychological distress, however, coping self-efficacy was a protective feature (Shahrour \& Dardas, 2020).

In another study conducted in the Sichuan Province of China, the relationship between resilience and stress was assessed among 600 medical staff of 32 hospitals, recruited from the radiology departments. There was a significant negative correlation between resilience and perceived stress. The independent influencing factors of resilience were gender, total perceived stress score, information of COVID-19, information of COVID-19 protective measures, and availability of said protective measures (Huan et al., 2020).

\section{Aims and Objectives}

It is known that COVID-19 has placed a significant burden on healthcare professionals. Due to the uncertainty attached, the time required to produce a vaccine, the fear of contracting and spreading the virus, addressing the fatalities due to the virus, having to wear uncomfortable personal protective equipment for long hours, it is normal that healthcare professionals will experience stress. It is therefore the aim of this study to understand the levels of stress and 


\section{Cross-sectional Study to Assess Psychological Impact of COVID-19 on Health Care Staff Working in a Tertiary Care Teaching Hospital}

anxiety of both frontline and second-line hospital workers. To gauge a holistic understanding, their levels of resilience and proactive coping will also be assessed. Additionally, the aim is to understand the correlation amongst the variables stress, anxiety, resilience and proactive coping. If it is found that they are experiencing high levels of distress and anxiety, urgent mental health interventions can be provided which will prevent them from further worsening their mental health and eventually, burn out.

\section{MATERIALS AND METHODS}

The current cross-sectional study hypothesized that all variables under study would be high. It was hypothesized that stress and anxiety would negatively correlate with both levels of resilience and proactive coping.

After receiving the university's Independent Ethics Committee approval, the sample was collected from a tertiary care teaching hospital unit, designated as a COVID-19 hospital in the district of Pune. The participants were briefed about the study over mail as well as over the phone and were sent an online Google form containing the survey questions that needed to be answered. Approximately 650 hospital employees, both frontline and second-line workers were contacted. 162 participants filled up the survey which contained a study outline, an informed consent form, questions concerning demographic details, and the four questionnaires. The four questionnaires used were, the Brief Resilience Scale (BRS) to assess levels of resilience, the Proactive Coping Scale (PCS) to assess proactive coping levels, the Perceived Stress Scale (PSS) to assess stress levels and the Zung Self-rating Anxiety Scale (SAS) to assess levels of anxiety. By eliminating double responses and those that declined to consent, the final number of responses counted was 151 . The softwares used to analyze the statistics were Microsoft Excel and R. Pearson's correlations were used to establish the correlations. Chi square tests and analysis of variance were used to elicit mean differences between the sexes and type of hospital worker, frontline versus second-line workers.

\section{RESULTS}

\section{Sociodemographic Profile}

Table 1 outlines the summary of demographic variables based on a sex split, collected from the sample which included questions about whether they were married, designation in the hospital, the number of family members they resided with, and whether any were considered vulnerable to COVID-19 (an individual under 10 years or above 65 years of age), duration of work hours, level of subjective fear they were experiencing given the situation and their satisfaction with hospital facilities taken to battle the pandemic. As the table denotes, there were no significant differences between sexes on any of the demographic variables that were collected. The mean age of the sample was 34.9 years old. 112 were 40 years and below, whereas only 39 were 41 years and above.

Table 1 Demographic and sample characteristics by sex.

\begin{tabular}{|c|c|c|c|c|}
\hline Characteristic & Total n(\%) & $\begin{array}{l}\text { Male } \\
\text { n(\%) }\end{array}$ & $\begin{array}{l}\text { Female } \\
\mathrm{n}(\%)\end{array}$ & P-value \\
\hline Number of participants & $151(100)$ & $74(49)$ & $77(51)$ & - \\
\hline Marital Status & & & & \\
\hline Never-married & $51(33.8)$ & $22(29.7)$ & $29(37.7)$ & 0.303 \\
\hline Ever-married & $100(66.2)$ & $52(70.3)$ & $48(62.3)$ & \\
\hline $\begin{array}{l}\text { Type of Hospital Worke } \\
\text { Frontline Worker }\end{array}$ & $68(45)$ & $35(47.3)$ & $33(42.8)$ & 0.584 \\
\hline
\end{tabular}




\begin{tabular}{|c|c|c|c|c|}
\hline Characteristic & Total n(\%) & $\begin{array}{l}\text { Male } \\
\text { n(\%) }\end{array}$ & $\begin{array}{l}\text { Female } \\
n(\%)\end{array}$ & P-value \\
\hline Second-line Worker & $83(55)$ & $39(52.7)$ & $44(57.2)$ & \\
\hline \multicolumn{5}{|c|}{ Number of family members they are residing with } \\
\hline 3 and below & $90(59.6)$ & $41(55.5)$ & $49(63.6)$ & \multirow[t]{2}{*}{0.303} \\
\hline 4 and above & $61(40.4)$ & $33(44.5)$ & $28(36.4)$ & \\
\hline \multicolumn{5}{|c|}{ Staying with a high-risk individual (anybody under 10yrs and over 65yrs) } \\
\hline Yes & $59(39.1)$ & $31(41.9)$ & $28(36.4)$ & \multirow{2}{*}{0.486} \\
\hline No & $92(60.9)$ & $43(58.1)$ & $49(63.6)$ & \\
\hline \multicolumn{5}{|c|}{ Duration of time spent in the hospital } \\
\hline 8 and below & $98(64.9)$ & $46(62.2)$ & $52(67.5)$ & \multirow{2}{*}{0.489} \\
\hline 9 and above & $53(35.1)$ & $28(37.8)$ & $25(32.5)$ & \\
\hline \multicolumn{5}{|c|}{ Level of fear associated with current situation } \\
\hline Low & $92(60.9)$ & $46(62.2)$ & $46(59.8)$ & \multirow[t]{3}{*}{0.822} \\
\hline Moderate & $40(26.5)$ & $18(24.3)$ & $22(28.6)$ & \\
\hline High & $19(12.6)$ & $10(13.5)$ & $9(11.7)$ & \\
\hline \multicolumn{5}{|c|}{ Level of satisfaction with hospital facilities } \\
\hline Low & $15(10)$ & $9(12.2)$ & $6(7.8)$ & \multirow[t]{3}{*}{0.181} \\
\hline Moderate & $60(39.7)$ & $24(32.4)$ & $36(46.7)$ & \\
\hline High & $76(50.3)$ & $41(55.4)$ & $35(45.5)$ & \\
\hline
\end{tabular}

Table 2 demonstrates a summary of demographic and study variables based on whether the respondent was a frontline worker or a second-line worker. Out of 151 participants, 68 were frontline workers and 83 were second-line workers. As per the table, there were a significantly higher number of frontline workers who were married at some point. There is also a significant difference between the levels of fear associated with the current situation between frontline and second-line workers. The results indicated that the frontline workers were experiencing higher levels of fear and that this finding was statistically significant $(\mathrm{p}=0.019)$.

Table 2 Demographic and sample characteristics by type of hospital worker.

\begin{tabular}{|c|c|c|c|c|}
\hline Characteristic & Total $\mathbf{n}(\%)$ & $\begin{array}{l}\text { Frontline } \\
\text { worker n(\%) }\end{array}$ & $\begin{array}{l}\text { Second-line } \\
\text { worker n(\%) }\end{array}$ & p-value \\
\hline Number of participants & $151(100)$ & $68(45)$ & $83(55)$ & \\
\hline \multicolumn{5}{|l|}{ Marital Status } \\
\hline Never-married & $51(33.8)$ & $32(53)$ & $19(32.9)$ & \multirow[t]{2}{*}{$0.002 * *$} \\
\hline Ever-married & $100(66.2)$ & $36(47)$ & $64(77.1)$ & \\
\hline \multicolumn{5}{|l|}{ Gender } \\
\hline Male & $74(49)$ & $35(51.5)$ & $39(47)$ & \multirow[t]{2}{*}{0.584} \\
\hline Female & $77(51)$ & $33(48.5)$ & $44(53)$ & \\
\hline \multicolumn{5}{|c|}{ Number of family members they are residing with } \\
\hline 3 and below & $90(59.6)$ & $45(66.2)$ & $45(54.2)$ & \multirow[t]{2}{*}{0.136} \\
\hline 4 and above & $61(40.4)$ & $23(33.8)$ & $38(45.8)$ & \\
\hline \multicolumn{5}{|c|}{ Staying with a high-risk individual (anybody under 10yrs and over 65yrs) } \\
\hline Yes & $59(39.1)$ & $22(32.3)$ & $37(44.6)$ & \multirow{2}{*}{0.126} \\
\hline No & $92(60.9)$ & $46(67.6)$ & $46(55.4)$ & \\
\hline \multicolumn{5}{|c|}{ Duration of time spent in the hospital } \\
\hline 8 and below & $98(64.9)$ & $46(67.6)$ & $52(62.6)$ & \multirow[t]{2}{*}{0.522} \\
\hline 9 and above & $53(35.1)$ & $22(32.4)$ & $31(37.4)$ & \\
\hline \multicolumn{5}{|c|}{ Level of fear associated with current situation } \\
\hline Low & $92(60.9)$ & $43(63.2)$ & $49(59)$ & \multirow[t]{3}{*}{$0.019 *$} \\
\hline Moderate & $40(26.5)$ & $12(17.6)$ & $28(33.7)$ & \\
\hline High & 19 (12.6) & $13(19.1)$ & $6(7.3)$ & \\
\hline
\end{tabular}




\begin{tabular}{lclll}
\hline Characteristic & Total $\mathbf{n}(\%)$ & $\begin{array}{l}\text { Frontline } \\
\text { worker } \mathbf{n}(\%)\end{array}$ & $\begin{array}{l}\text { Second-line } \\
\text { worker n(\%) }\end{array}$ & p-value \\
\hline Level of satisfaction with hospital facilities & & & \\
Low & $15(10)$ & $10(14.7)$ & $5(6)$ & 0.178 \\
Moderate & $60(39.7)$ & $24(35.3)$ & $36(43.4)$ & \\
High & $76(50.3)$ & $34(50)$ & $42(50.6)$ & \\
\hline
\end{tabular}

$* * \mathrm{p}<0.01$.

$* \mathrm{p}<0.05$.

\section{CLINICAL PROFILE}

Table 3 reveals that only (12) 7.94\% of the total sample was experiencing high levels of stress, (122) $80.79 \%$ were experiencing moderate levels and the remaining $17(11.25 \%)$ were experiencing low levels of stress. The mean score for the total group was 20.03 and standard deviation was 6.07 which signifies a moderate level experience of stress.

Analyzing the health professionals' levels of anxiety, showed that $140(92.71 \%)$ of people in the group had normal levels of anxiety and only (11) $7.28 \%$ were experiencing mild to moderate levels of anxiety. None of the participants' scores indicated severe or extreme levels of anxiety. The mean score for the total group was 36.21 and the standard deviation was 5.68. The resilience level of the sample was moderate, with a mean score of 20.01 and standard deviation of 4.15. Only (23) $15 \%$ of the sample portrayed high levels of resilience, (91) 60.26 $\%$ fell in the moderate category and (37) $24.50 \%$ showed lower levels of resilience.

The mean score of 45.11 and SD of 6.05 of the sample on the proactive coping scale indicated that the group employed high levels of proactive coping techniques. The scale does not provide a direct interpretation of scores, however, the higher the score the more proactive strategies are being used by the person to cope with a stressful scenario. The scores range from 14 as a minimum score to 56 as a maximum score. $135(89.40 \%)$ of the sample scored towards the higher end of implementing proactive coping strategies, $16(10.59 \%)$ scored moderate and none of the participants scored low on this variable.

It was hypothesized that the hospital professionals would be experiencing high levels of stress and anxiety whilst tending to COVID-19 patients, however, the scores indicate that most of them were experiencing moderate levels of stress and normal levels of anxiety, therefore these two hypotheses were rejected. It was also hypothesized that hospital professionals treating COVID-19 patients would have high levels of resilience and use higher levels of proactive coping techniques. It was found that most of the sample scored moderately on resilience, therefore partially accepting this hypothesis. However, it was found that most of the sample did use higher levels of proactive coping techniques, therefore, accepting this hypothesis.

Table 3 Total scores, percentage and range on the variables of Stress, Anxiety, Resilience and Coping Style.

\begin{tabular}{llll}
\hline Variables & Scores & Percentage & Range \\
\hline Stress & 17 & $11.25 \%$ & High \\
& 122 & $80.79 \%$ & Moderate \\
& 12 & $7.94 \%$ & Low \\
\hline
\end{tabular}




\begin{tabular}{llll}
\hline Variables & Scores & Percentage & Range \\
\hline Anxiety & 140 & $92.71 \%$ & Normal \\
& 11 & $7.28 \%$ & Mild/Moderate \\
& 0 & $0 \%$ & Severe/Extreme \\
\hline Resilience & 37 & $24.50 \%$ & High \\
& 91 & $60.26 \%$ & Moderate \\
& 23 & $15 \%$ & Low \\
\hline Proactive coping & 135 & $89.40 \%$ & High \\
& 16 & $10.59 \%$ & Moderate \\
& 0 & $0 \%$ & Low \\
\hline
\end{tabular}

\section{Correlations}

To study the interactive effect of coping and resilience on stress and anxiety, Pearson's correlation coefficients were calculated and the results indicated that there was a significant positive correlation $(r=0.3707)$ between resilience and coping at $p=0.000$ level. There was also a mild significant negative correlation $(r=-0.1763)$ between anxiety and resilience at $p$ $=0.0303$. However, there is no significant correlation found between resilience and stress. Neither is there a significant correlation between coping and stress nor a significant correlation found between coping and anxiety. Stress and anxiety did not prove to be significantly correlated either as seen in Table 4.

As per the results, all the correlation hypotheses were rejected except for the one that predicted a significant negative correlation between anxiety and resilience levels.

Table 4 Pearson Correlations of the Four Variables - Resilience, Coping, Stress and Anxiety.

\begin{tabular}{llllllll}
\hline Variable & n & M & SD & SAS & PSS & BRS & PCS \\
\hline SAS (Anxiety) & 151 & 36.20 & 5.68 & - & & & \\
PSS (Stress) & 151 & 20.03 & 6.06 & -0.0012 & - & & \\
BRS (Resilience) & 151 & 20.01 & 4.15 & $-0.1763^{*}$ & -0.0204 & - & \\
PCS (Proactive coping) & 151 & 45.10 & 6.09 & -0.0904 & 0.1270 & $0.3707^{* *}$ & -
\end{tabular}

** Correlation is significant at a $<0.001$ level (2-tailed).

* Correlation is significant at a 0.05 level (2-tailed).

\section{DISCUSSION}

Out of the total health care workers contacted to participate in the study, approximately $23 \%$ filled out the questionnaires. There are multiple reasons as to why less than a quarter of the population approached, participated in the study. Given they were contacted around May 2020 , the number of duties they were juggling due to the rapid increase in patients, could have been overwhelming. There were also multiple studies being conducted as the hospital was a designated COVID-19 one, leaving lesser time for professionals to partake in yet another 


\section{Cross-sectional Study to Assess Psychological Impact of COVID-19 on Health Care Staff Working in a Tertiary Care Teaching Hospital}

study. The study was also online and responses are usually higher when a study is conducted face to face. As per the responses gathered concerning the health care professionals being satisfied with the hospital facilities, the results stated that $136(90 \%)$ of the sample were moderate to highly satisfied. One could presume that the majority of the hospital staff were also satisfied with the way the situation was being handled and therefore, chose to not participate in a study aimed at studying their psychological health as a result of the pandemic. The results also suggest that approximately $132(87 \%)$ of the sample experienced low to moderate fear for the current situation, which supports the aforementioned assumption. However, a qualitative study to understand these reasons would help cement this claim.

Doctors are known to experience higher stress, anxiety, and depression levels in comparison to the general population (Sherlock \& John, 2016). A novel pandemic is a unique situation that has placed an increased burden on health care professionals. In reference to this, it was hypothesized the group under study will experience high levels of stress as a similar trend was found in an Italian study which stated that there is growing evidence that COVID-19 can be an self-determining risk factor for stress in health care professionals.(20) The second variable under study was anxiety and it was hypothesized that the group will experience high levels of anxiety due to the demands that the pandemic has placed upon them, which is supported by the literature. The results of the current study partially support the hypothesis that stress levels will be high as the hospital staff is seen to be experiencing moderate stress levels. The mean score on the stress scale showed that both the frontline and second-line workers and sexes were experiencing similar levels of stress. The scores lie on a moderate level as per the norms of the scale. Similar results were found in a study conducted on the Indian healthcare population where $341(78.9 \%)$ members of their sample were experiencing moderate to highstress levels (Giusti et al., 2020). However, unlike the stated study, female sex was not a predictor for higher stress levels. The results also do not support the second hypothesis as the anxiety scores of the sample are found to be in the normal range as per the mean scores, dictated by the norms of the test. $33(7.28 \%)$ of the sample scored moderate levels of anxiety. In a similar cross-sectional study conducted in Italy during the coronavirus pandemic, mental health outcomes among health care workers were reported. Only $114(8.27 \%)$ of the sample showed symptoms of anxiety similar to the results of the current study (Rossi et al., 2020). The mean score for frontline and second-line workers indicated that the groups did not differ significantly on the levels of anxiety experienced by the workers who are in direct contact with the patients versus those who are not. No sex differences were reported either. A plausible explanation as to why the stress levels were moderate and not high and anxiety levels was low is that $90 \%$ of the sample was satisfied with the hospital facilities such as the quality and quantity of safety equipment, awareness of measures being taken by the hospital, which aided in preventing the distress from exacerbating to high, uncontrollable levels leading to anxiety. The participants also scored high on resilience and reported employing proactive coping strategies. A study conducted in the United States of America on a large population of healthcare and non-healthcare professionals found that health care professionals who scored higher on resilience worried significantly lesser than those who scored lower on resilience. They also scored lower on levels of anxiety (Barzilay et al., 2020). The variables were correlated in the current study to understand if there was a relationship between them. The only significant negative correlation was found between anxiety and resilience. A moderately significant positive correlation was also noted between levels of resilience and proactive coping. Hence, it can be presumed that the higher the scores on resilience, the lower the levels of anxiety in the given sample, which bolsters the protective effects of resilience on stress and anxiety. Since there is also a significant positive correlation between resilience and proactive 


\section{Cross-sectional Study to Assess Psychological Impact of COVID-19 on Health Care Staff Working in a Tertiary Care Teaching Hospital}

levels of coping, further studies can be conducted to understand whether proactive coping strategies play a moderating role in the negative relationship between resilience and anxiety.

The results of applying proactive coping techniques and levels of resilience support the hypothesis. The scores show the group has ample proactive skills to cope with distress and innate resilience which enabled them to maintain controlled levels of anxiety and a moderate level of stress. It is normal for people, especially healthcare professionals to undergo stress in a situation where an abundance of uncertainty is involved and the situation places chronic pressure on the limited resources available to battle it. It is known that acute stress response probably would not place a burden on young and healthy individuals, however, chronic stress response can cause deleterious effects (Schneiderman, Ironson \& Siegel, 2005). COVID-19 entered India at the end of January 2020, however, the nation went into lockdown in the mid of March. The data for the current study were collected between May and July and the mean age of the sample was 34 years, with approximately $110(70 \%)$ being under 40 years of age. Age is seen as a protective factor, in this case, wherein older adults tend to experience higher negative affect with respect to daily stressors (Mroczek \& Almeida, 2004). It can be hypothesized that the health care professionals currently under analysis were still experiencing an acute stress response, due to which, they were enabled to use their innate resources of resilience and proactive coping as a result of the moderate stress and low anxiety that they were experiencing. This prevented them from developing any mental health disorders as a result. It would be worthy to study the same sample six months later, on the same variables, to understand the chronic effects of the stress brought on by COVID-19 since it is still an ongoing battle. The tertiary care center under study was also newly established with state-of-theart supplies. Therefore, it is likely that the readiness brought on by new facilities, a new task force, and better preparedness acted as protective factors in shielding the health care professionals from high stress which would culminate into psychopathology.

\section{CONCLUSION}

In conclusion, it can be noted that the current sample of health care professionals under study was experiencing a low to moderate impact upon their mental health, during the COVID-19 pandemic. They were experiencing moderate stress levels and most reported normal levels of anxiety. It was interesting to note that most scored high on resilience and were using higher levels of proactive coping strategies to battle the mental health consequences resulting from the pandemic. Most reported being satisfied with the hospital facilities and low levels of fear associated with the current situation which supports the claim that the pandemic impacted their mental health in a moderated amount. This is also further supported by the negative correlation between anxiety and resilience and the positive correlation between resilience and proactive coping techniques, which was expected. Therefore, it can be concluded that innate resilience, using proactive coping techniques and adequate support from the hospital can protect those under acute strain from the pandemic from letting their stress response culminate into psychiatric morbidity.

However, the results must be interpreted by keeping in mind that the sample size was limited. Less than a quarter of the hospital employees participated in the study, despite reaching out to them repeatedly. The private hospital was newly established, with advanced infrastructure and facilities, therefore providing adequate and timely support to the health care professionals. Since the questionnaire responses were conducted within the first few months of the onset of the pandemic, it may be more representative of a cross-sectional, acute psychological response to the pandemic. A longitudinal study would provide a more accurate representation of the

(c) The International Journal of Indian Psychology, ISSN 2348-5396 (e)| ISSN: 2349-3429 (p) | 1409 
chronic response to stress caused by a pandemic that appears here to stay. It would also be interesting to study the psychological effects experienced by healthcare workers in public hospitals, where the facilities and support provided to the healthcare workers are different. Another future line of research that could be explored is whether resilience reserves and tendencies to use proactive coping strategies may sustain or burnout in the face of long-term, chronic stressors. This would highlight the importance of offering mental health support such as providing access to stress management workshops to those fighting the pandemic around the clock, with limited resources, on the verge of burnout.

\section{REFERENCES}

\#India Fights Corona COVID-19, (2021). MyGov.in. Retrieved from: https://www.mygov.in/covid-19/

Anxiety, (n.d.). APA Dictionary of Psychology. Retrieved from https://dictionary.apa.org/anxiety

Barzilay R., Moore T. M., Greenberg D. M., DiDomenico G. E., Brown L. A., White L. K., et al., (2020). Resilience, COVID-19-related stress, anxiety and depression during the pandemic in a large population enriched for healthcare providers. Transl. Psychiatry 10, 1-8. 10.1038/s41398-020-00982-4

Bhushan, R., (2020). Doctors, the vanguard of COVID-19 response, face crippling shortage of protective gear. Money Control. Retrieved from: https://www.moneycontrol.com/news/india/doctors-the-vanguard-of-covid-19response-face-crippling-shortage-of-protective-gear-5101091.html

Coping, (n.d.). APA Dictionary of Psychology. Retrieved from https://dictionary.apa.org/coping

COVID-19, MERS \& SARS, (2021). Niaid.nih.gov. Retrieved from: https://www.niaid.nih.gov/diseases-conditions/covid-19

Gallagher, J., (2020). How close to developing a vaccine are we? BBC. Retrieved from: https://www.bbc.com/news/health-51665497.dit

Giusti, E. M., Pedroli, E., D'Aniello, G. E., Stramba Badiale, C., Pietrabissa, G., Manna, C., Stramba Badiale, M., Riva, G., Castelnuovo, G., \& Molinari, E. (2020). The Psychological Impact of the COVID-19 Outbreak on Health Professionals: A Cross$\begin{array}{llll}\text { Sectional Study. Frontiers in } & 1684 .\end{array}$ https://doi.org/10.3389/fpsyg.2020.01684

Hacimusalar, Y., Kahve, A. C., Yasar, A. B., \& Aydin, M. S. (2020). Anxiety and hopelessness levels in COVID-19 pandemic: A comparative study of healthcare professionals and other community sample in Turkey. Journal of psychiatric research, 129, 181-188. https://doi.org/10.1016/j.jpsychires.2020.07.024

Huang, L., Wang, Y., Liu, J., Ye, P., Cheng, B., Xu, H., Qu, H., \& Ning, G. (2020). Factors Associated with Resilience Among Medical Staff in Radiology Departments During The Outbreak of 2019 Novel Coronavirus Disease (COVID-19): A Cross-Sectional Study. Medical science monitor : international medical journal of experimental and clinical research, 26, e925669. https://doi.org/10.12659/MSM.925669

Kang, L., Li, Y., Hu, S., Chen, M., Yang, C., Yang, B. X., Wang, Y., Hu, J., Lai, J., Ma, X., Chen, J., Guan, L., Wang, G., Ma, H., \& Liu, Z. (2020). The mental health of medical workers in Wuhan, China dealing with the 2019 novel coronavirus. The lancet. Psychiatry, 7(3), e14. https://doi.org/10.1016/S2215-0366(20)30047-X

Lai, J., Ma, S., Wang, Y., Cai, Z., Hu, J., Wei, N., Wu, J., Du, H., Chen, T., Li, R., Tan, H., Kang, L., Yao, L., Huang, M., Wang, H., Wang, G., Liu, Z., \& Hu, S. (2020). Factors Associated With Mental Health Outcomes Among Health Care Workers Exposed to 
Coronavirus Disease 2019. JAMA network open, 3(3), e203976. https://doi.org/10.1001/jamanetworkopen.2020.3976

Liu, S., Yang, L., Zhang, C., Xiang, Y. T., Liu, Z., Hu, S., \& Zhang, B. (2020). Online mental health services in China during the COVID-19 outbreak. The lancet. Psychiatry, 7(4), e17-e18. https://doi.org/10.1016/S2215-0366(20)30077-8

McCain, R. S., McKinley, N., Dempster, M., Campbell, W. J., \& Kirk, S. J. (2017). A study of the relationship between resilience, burnout and coping strategies in doctors. Postgraduate medical journal, postgradmedj-2016-134683. Advance online publication. https://doi.org/10.1136/postgradmedj-2016-134683

Mroczek, D. K., \& Almeida, D. M. (2004). The effect of daily stress, personality, and age on daily negative affect. Journal of personality, 72(2), 355-378. https://doi.org/10.1111/j.0022-3506.2004.00265.x

Nickell, L. A., Crighton, E. J., Tracy, C. S., Al-Enazy, H., Bolaji, Y., Hanjrah, S., Hussain, A., Makhlouf, S., \& Upshur, R. E. (2004). Psychosocial effects of SARS on hospital staff: survey of a large tertiary care institution. CMAJ : Canadian Medical Association journal = journal de l'Association medicale canadienne, 170(5), 793-798. https://doi.org/10.1503/cmaj.1031077

Que, J., Shi, L., Deng, J., Liu, J., Zhang, L., Wu, S., Gong, Y., Huang, W., Yuan, K., Yan, W., Sun, Y., Ran, M., Bao, Y., \& Lu, L. (2020). Psychological impact of the COVID19 pandemic on healthcare workers: a cross-sectional study in China. General psychiatry, 33(3), e100259. https://doi.org/10.1136/gpsych-2020-100259

Rajkumar R. P. (2020). COVID-19 and mental health: A review of the existing $\begin{array}{llll}\text { literature. Asian journal of psychiatry, 52, } & 102066 .\end{array}$ https://doi.org/10.1016/j.ajp.2020.102066

Resilience, (n.d.). APA Dictionary of Psychology. Retrieved from https://dictionary.apa.org/resilience

Rossi, R., Socci, V., Pacitti, F., Di Lorenzo, G., Di Marco, A., Siracusano, A., \& Rossi, A. (2020). Mental Health Outcomes Among Frontline and Second-Line Health Care Workers During the Coronavirus Disease 2019 (COVID-19) Pandemic in Italy. JAMA network open, 3(5), e2010185. https://doi.org/10.1001/jamanetworkopen.2020.10185

Schneiderman, N., Ironson, G., \& Siegel, S. D. (2005). Stress and health: psychological, behavioral, and biological determinants. Annual review of clinical psychology, 1, 607628. https://doi.org/10.1146/annurev.clinpsy.1.102803.144141

Shahrour, G., \& Dardas, L. A. (2020). Acute stress disorder, coping self-efficacy and subsequent psychological distress among nurses amid COVID-19. Journal of nursing management, 28(7), 1686-1695. https://doi.org/10.1111/jonm.13124

Sherlock, C., \& John, C. (2016). Adaptation practice: teaching doctors how to cope with stress, anxiety and depression by developing resilience. British Journal of Medical Practitioners, 9(2), $42+$.

Stress, (n.d.). APA Dictionary of Psychology. Retrieved from https://dictionary.apa.org/stress

Wilson, W., Raj, J. P., Rao, S., Ghiya, M., Nedungalaparambil, N. M., Mundra, H., \& Mathew, R. (2020). Prevalence and Predictors of Stress, anxiety, and Depression among Healthcare Workers Managing COVID-19 Pandemic in India: A Nationwide Observational Study. Indian Journal of Psychological Medicine, 42(4), 353358. https://doi.org/10.1177/0253717620933992 


\section{Acknowledgement}

The authors of the paper would like to deeply thank Dr. Sudeep Bapat and Dr. Sharvari Shukla for their support. They would also like to mention Ms. Mithilesh Mishra's help that was provided during the process of this project. The assistance of the hospital staff, both who participated and those that helped us along the way is greatly appreciated.

\section{Conflict of Interest}

The author(s) declared no conflict of interest.

How to cite this article: Mahale G., Thadaney Y. \& Purohit N. (2021). Cross-sectional Study to Assess Psychological Impact of COVID-19 on Health Care Staff Working in a Tertiary Care Teaching Hospital. International Journal of Indian Psychology, 9(2), 1400-1412. DIP:18.01.144.20210902, DOI:10.25215/0902.144 